\title{
Participación política de las personas con discapacidad en el Ecuador
}

\section{Political Participation of Disabled Citizens in Ecuador}

\section{Arturo Moreno Andrade}

Recepción: 4 de julio de 2014 Aceptación: 9 de agosto de 2014

\section{Resumen}

El artículo identifica los avances en el ejercicio de los derechos de participación de las personas con discapacidad en el Ecuador y los diversos factores que han influenciado. Inicia con un análisis de la influencia del pensamiento griego en la interacción social y el ejercicio de derechos de participación de las personas durante el tiempo para posteriormente llegar a la concepción de democracia como un modelo de gobierno que permite acercar a la participación de lo público y garantizar los derechos humanos de los grupos discriminados. El artículo termina mostrando el trabajo desarrollado por el Consejo Nacional Electoral del Ecuador en relación a la inclusión de las personas con discapacidad en los procesos electorales recientes, a través de indicadores de participación política. El artículo termina con un resumen de las principales lecciones aprendidas y las experiencias exitosas en cuanto a la gestión de la institución.

Palabras claves: democracia, igualdad, integración, participación política, derechos humanos.

\section{Abstract}

This article identifies the progress made in the realm of rights of participation of people with disabilities in Ecuador and the various factors that have influenced it. It begins with an analysis of the influence of Greek thought in social interaction and the exercise of participation rights of people over time, in order to arrive to a notion of democracy as a governance model approach that allows public participation of discriminated groups. The article continues by showing the work done by the National Electoral Council of Ecuador in relation to the inclusion of people with disabilities in the latest electoral processes, mainly, through indicators of political participation. The paper concludes with a summary of the main lessons learned by the institution as well as experiences that accounts successful management.

Keywords: democracy, equality, integration, political participation, human rights. 


\section{La visión aristotélica de los “otros" y su influencia contemporánea}

T a democracia no fue siempre el modelo de gobierno mejor considerado por los habitantes de una nación como en el día de hoy. En realidad, el filósofo griego Platón, 400 años A.C., afirmaba que el desorden de la democracia conducía a la tiranía y que incluso fomenta la inmoralidad de cada uno, que el ser elegido como autoridad no garantizaba su desempeño como tal (Giménez, 2008).

Pero no solo estaba detrás esta condición de capacidad o incapacidad para la determinación de quienes eran los más aptos para dirigir o gobernar, sino también la visión del ser humano de la época, tanto como hombre o mujer y sus diversos momentos etarios, como por sus condiciones sociales; según este filósofo, el ser humano se componía del alma como esencia y el cuerpo como su instrumento para su servicio.

En este sentido los seres humanos estaban en la obligación moral de desarrollar su esencia para que cuando se desprenda del cuerpo se pueda llegar a su perfección o a su salvación. Según Platón el alma tenía tres elementos, que, según su predominio, definían inclusive la participación política:

"Aquellos en los que predomina lo racional son los filósofos, los de apasionado carácter deben ser los guardianes, y los otros, los voluptuosos y amantes de lo material y la riqueza, los trabajadores. En la ciudad justa ideal de la Politeia platónica, solo existente en un plano utópico, cada individuo ocuparía el lugar que merece por la composición de su alma. Arriba los filósofos gobernantes, luego los aguerridos guardianes, y abajo la sensual y codiciosa masa obrera" (García, 2003).

Por lo tanto se empezó a identificar los posibles inicios de la diferenciación de género ya que la mujer era considerada con esencia inferior al igual que los nińos y niñas por estar en proceso de crecimiento físico y del alma. Junto con ellos los esclavos, los adultos mayores e incluso las personas con alguna enfermedad o deficiencia; a estos grupos por lo general se los consideraban como parte de los "otros". 
El modelo de gobierno entonces no solo era una cuestión de aptitudes sino de concepciones del ser humano en general, en ese sentido los "otros" no participaban de las decisiones de la administración de lo público, de los debates para la construcción del pensamiento e incluso, de los espacios educativos que desarrollaban la razón. El espacio al cual estaban designados era el privado y por lo general el doméstico.

En este contexto la democracia sería inapropiada; es decir, ¿cómo podría un "otro" decidir sobre la administración de los servicios públicos de la población? En efecto la democracia no tenía cabida en este contexto mientras las personas sean concebidas como personas diferentes y con esencia inferior; por lo tanto, sus aportes serían menos válidos que los aportes de los demás. Se podría decir entonces que la discriminación parte del reconocimiento del otro como diferente e inferior y no como diferente e igual. Esta misma visión de las personas se mantiene en la actualidad y conserva el proceso de exclusión de estas poblaciones en algunos aspectos de los modelos de gobierno empleados por las sociedades.

En los últimos siglos, otras manifestaciones históricas del entendimiento del ser humano como diferente e inferior podrían considerarse. Por un lado, la revolución francesa con sus preceptos de libertad, igualdad y fraternidad, la cual halló cabida entre los pobladores o habitantes del reino de Francia, y que posteriormente sirvió como ejemplo para la grandes luchas y conquistas libertarias en todo el mundo. Por otro lado, la segunda guerra mundial, resultado de la ideología nazista, donde el núcleo central era la tesis de la superioridad de la raza aria, destinada a dominar y "limpiar étnicamente" el mundo. Las distintas formas de racismo se tradujeron primero en leyes que limitaban los derechos civiles de los hebreos, que después fueron objeto de exterminio durante la guerra (Cisneros, 2002).

Posterior a estos eventos todos los Estados del mundo deciden acordar la igualdad de los seres humanos y el respeto de su dignidad concibiéndolo eso si como diferente pero igual. Es así que resultan los muy conocidos Derechos Humanos y la Organización de las Naciones Unidas. 
Pero ¿fue suficiente este reconocimiento del otro como diferente pero igual? , a partir de 1948 ¿todos los seres humanos del mundo o al menos de los Estados parte de la Organización de las Naciones Unidas fueron considerados como iguales? Si la respuesta fuese afirmativa entonces, ¿por qué un año después, en 1949, se firma el convenio para la represión de la trata de personas y de la explotación de la prostitución ajena o la Convención sobre los Derechos del Niño, adoptada y abierta a la firma y ratificación por la Asamblea General en 1989, la cual entra en vigor en 1990? Por supuesto se consideró solo a los niños y más no explícitamente a las niñas. Cuarenta y seis años después, en 1994, se firma la Convención Interamericana para Prevenir, Sancionar y Erradicar la Violencia contra la Mujer en Belén Do Para. Y como último ejemplo la Convención Internacional sobre los Derechos de las Personas con Discapacidad la cual entro en vigor en el año 2008. ¿¿Fue necesario entonces afianzar los derechos humanos de aquellos que alguna vez fueron considerados como parte de los "otros”? ¿Es posible que al momento de generarse estos instrumentos internacionales, estas personas seguían siendo consideradas como diferentes e inferiores?

Posiblemente entonces, el origen y la causa de la exclusión durante la historia hasta nuestro tiempo ha sido la forma de ver a los seres humanos como diferentes e inferiores y no como diferentes e iguales, que a su vez en términos específicos es una no incorporación a la comunidad social y política, la negación sistémica de derechos de ciudadanía, la desigualdad del tratamiento ante la ley y las instancias públicas (Fleury, 2003) y a los beneficios del desarrollo, provocando además una separación de la esfera pública. De todas maneras hay que desarrollar todavía la concepción de lo diferente, no como aquellos elementos que nos clasifican o nos agrupan, sino como aquellos que nos asemejan y que nos unen, como lo mencionaba el ex vicepresidente de la República del Ecuador Lenín Moreno en el discurso de inauguración del Congreso América Solidaria: 
"Los antropólogos hablan de la "otredad", es decir de la existencia del otro, del distinto a mí. Una realidad que existe y está junto a cada uno de nosotros.

Porque el otro, significa distinto, diferente, preferimos sabernos similares y buscar en qué nos parecemos. Hacer de la otredad una mismidad." (Moreno, 2012).

\section{La democracia como modelo de gobierno que permite y propicia la visión de la humanidad como diferente pero igual}

El demos que significa pueblo en el idioma griego, como concepto permite el reconocimiento a todos los habitantes de una sociedad como parte activa de la misma, como sujetos diferentes e iguales frente a otros, con los mismos derechos y responsabilidades y con acceso a todos los espacios al igual que los demás.

Vivir en democracia implica, entre sus aspectos más importantes, que cualquier persona puede elegir un o una representante para que administre lo público o elegir una decisión sobre lo público directamente; así también cualquier persona puede ser elegida para representar y tomar decisiones e incluso puede participar en cualquier espacio de decisión pública durante cualquier momento de un gobierno.

A diferencia de vivir en un modelo aristocrático, las personas con discapacidad y todas aquellas que eran consideradas como los "otros", en el sistema democrático, pueden ser parte de lo político y dejar el espacio privado para participar en lo público; pueden además tener injerencia en los espacios de construcción de la sociedad como el educativo, organizacional, cultural, periodístico, deportivo, religioso, entre otros.

En este sentido la democracia moderna garantiza los derechos de todos los diferentes pero iguales y permite el ejercicio de los mismos a medida de la voluntad de cada ciudadano o ciudadana. Pero es importante acotar también que es responsabilidad, y en ciertos casos, obliga- 
ción de cada persona el nivel de ejercicio de sus derechos. Cabe acotar que lamentablemente aun los grupos de personas que han sido históricamente discriminadas, adoptan una posición pasiva de reclamo de garantías sin complementar con la apropiación del ejercicio de los derechos.

\section{Los retos de la sociedad moderna: ¿̨integración o inclusión?}

Sin duda los retos sociales y políticos son individuales y colectivos, y por supuesto en función de cada área del desarrollo de una sociedad, en ese sentido, frente a la exclusión o la discriminación, ¿`cuál sería el reto? ¿Incluir o Integrar? Según la Real Academia de la Lengua (2001) la palabra "incluir" se origina del latín 'inclusio', relacionada con la palabra 'includere' que significa literalmente 'encerrar', está conformada entonces de 'in-' (en) y 'claudere' (cerrar), poner una cosa dentro de otra o de sus límites, comprender en si o llevar consigo.

Por otro lado y de la misma fuente, la palabra "integrar" se origina del concepto latino "integratio", se trata de construir un todo con las partes que faltaban o reuniendo sus partes. Podría significar también, que alguien o algo pase a formar parte de un todo. Además entre sus sinónimos más relevantes encontramos la palabra "aunar" que implica fusionar dos o más elementos en uno solo que los sintetice.

En este sentido se consideraría la integración como el reto de una sociedad ante la discriminación o exclusión. Entonces, construir una nueva sociedad implica reinventar principalmente lo público y lo político, tomando en cuenta no solo un elemento por separado sino todos aquellos que le faltaban al mismo tiempo; esto requiere además hacer un esfuerzo por una visión común, que las personas con discapacidad y las organizaciones que trabajan en pro de sus derechos, ya no solo busquen la inclusión, sino su integración y la de los otros grupos también discriminados. Adicionalmente, y como condición fundamental, la integración debe ser el resultado de la libre decisión de participar, consiguiendo así el verdadero fin del desarrollo, que es la libertad de cada ser humano, de autodefinirse o autoconstruirse, cualquiera que sea el contexto o el espacio donde viva (Boisier, 2004). 
En otras palabras la integración es fusionar todos los ciudadanos y ciudadanas tanto de una manera individual como grupal y consolidar una nueva forma de convivencia ciudadana, en diversidad e incluso en armonía con la naturaleza.

\section{La integración de las personas con discapacidad en el Ecuador y la garantía de sus derechos de participación}

La discapacidad, lejos de ser una situación que diferencia a una persona de otra, es una realidad que "forma parte de la diversidad en el mundo" (Moreno, 2012); por lo tanto, es imprescindible tomarla en cuenta en el cumplimiento y promoción del ejercicio de los derechos civiles y políticos.

En el Ecuador y en los países de América Latina, las personas con algún tipo de discapacidad se constituyen como grupos prioritarios, ya que manifiestan mayores niveles de exclusión de los beneficios y resultados del desarrollo de cada contexto (OMS, 2011).

De acuerdo al artículo 11 de la Constitución de la República del Ecuador (2008), se establece que todas las personas son iguales y que gozarán de los mismos derechos, deberes y oportunidades, que nadie podrá ser discriminado por discapacidad, diferencia física, ni por cualquier otra distinción personal o colectiva. Así también, el Estado tiene la obligación de generar medidas de acción afirmativa que promuevan la igualdad real en favor de las personas que se encuentren en situación de desigualdad.

En lo que respecta a la participación política, el Consejo Nacional Electoral (CNE) tiene la misión de garantizar el ejercicio de los derechos políticos de la ciudadanía y de promover el fortalecimiento de la democracia; asegurando una participación equitativa, igualitaria, paritaria, intercultural, libre, democrática y justa para elegir y ser elegidos.

Es por eso que el CNE inició desde el 2011, un proceso de construcción de una política pública que permite establecer las condiciones necesarias para el ejercicio de los derechos políticos de las personas con discapacidad 
y de los grupos prioritarios con voto facultativo, a través de normativas, que fueron generadas en un trabajo conjunto con diversos actores.

En este sentido, en el mes de octubre de 2012, se construye un reglamento de participación política de las personas con discapacidad, denominado bajo el mismo nombre. Además, se crea un instructivo para el registro y sufragio de las personas del proyecto piloto "Voto en Casa" emitido en noviembre de 2013 y un instructivo para las mesas de atención preferente emitido durante el mes de enero de 2014.

El diseño, aplicación y evaluación de esta política pública y sus normativas, han sido resultado de un proceso participativo y constante de más de 1331 organizaciones públicas y privadas como las Federaciones Nacionales de y para la Discapacidad, las delegaciones provinciales del CNE y organizaciones de la sociedad civil en todo el país.

El presupuesto del organismo electoral invertido para la aplicación de esta política pública fue 107000 dólares para las elecciones generales del año 2013, que luego de evidenciar su impacto en la participación de las personas con discapacidad, el CNE decidió aumentar el presupuesto a 433360 dólares para las elecciones seccionales del ańo 2014.

\section{Impacto de la implementación de la política pública}

A continuación se muestran los resultados del ejercicio de los derechos de participación en el Ecuador divididos en tres partes. La primera muestra el ejercicio del derecho a elegir de los y las ciudadanas con discapacidad; la segunda evidencia el ejercicio mismo del derecho a ser elegido; y la tercera el derecho a participar del proceso electoral como evento público.

\section{Derecho a elegir}

De acuerdo al artículo 11 de la Ley Orgánica Electoral y de Organizaciones Políticas, Código de la Democracia, se establece que el voto será facultativo para las personas mayores de sesenta y cinco años de edad 
y las personas con discapacidad. Es así que el CNE solicitó la base de datos de personas con discapacidad mayores de 16 ańos para su empadronamiento al Consejo Nacional de Discapacidades (CONADIS) y al Ministerio de Salud Pública (MSP) con información adicional como: porcentaje de discapacidad, tipo de discapacidad, género, sector de vivienda, número de cédula y datos generales para el diseño, evaluación y aplicación de políticas públicas y medidas de acción afirmativa para la promoción del ejercicio de sus derechos de participación. El número de personas con discapacidad empadronados para el proceso electoral de 2013 fue de 279 624, cifra que aumentó para el 2014 a 304108 personas.

\section{Empadronamiento y cambio de domicilio}

En concordancia con el artículo 65 de la Constitución, en el que manifiesta que el Estado adoptará medidas de acción afirmativa para garantizar la participación de los sectores discriminados y además, debido a que más del 50\% de la personas con discapacidad mayores de 65 años no ejerció su derecho al sufragio en el proceso electoral de 2013, en su mayoría por: 1) no encontrarse empadronados en su lugar de residencia, 2) la situación de doble vulnerabilidad y 3) por la inaccesibilidad de los servicios de trasporte e infraestructura tanto del sector urbano como rural del país, se realizó una campaña denominada "Cambio de Domicilio" para las elecciones de 2013 y 2014, conformando 48 brigadas a nivel nacional.

Las brigadas de cambio de domicilio funcionaron de manera fija, colocando mesas con personal capacitado para el efecto en lugares y eventos estratégicos de asistencia masiva de las personas con discapacidad y adultos mayores, y de manera móvil, las cuales visitaron los domicilios de las personas de este grupo prioritario según la base de datos proporcionada por las instituciones que trabajan en este ámbito y de las organizaciones y movimientos asociativos (ver Tabla 1). 
Tabla 1.

Cambio de Domicilio

\begin{tabular}{c|c|c|c|c}
\hline \multirow{2}{*}{ Tipo } & \multicolumn{2}{|c|}{2013} & \multicolumn{2}{c}{2014} \\
\cline { 2 - 5 } & Electores & $\%$ & Electores & $\%$ \\
\hline Personas sin discapacidad & 481129 & $89,9 \%$ & 487830 & $90,4 \%$ \\
\hline Personas con discapacidad & 15338 & $2,9 \%$ & 15346 & $2,8 \%$ \\
\hline Adultos mayores & 38954 & $7,3 \%$ & 36538 & $6,8 \%$ \\
\hline Total & 535421 & $100,0 \%$ & 539714 & $100,0 \%$ \\
\hline
\end{tabular}

Fuente: Dirección Nacional de Estadística - CNE

Elaborado por: Proyecto de Inclusión de Personas con Discapacidad - CNE

\section{La accesibilidad de los recintos electorales}

La accesibilidad es la condición que deben cumplir los entornos, procesos, bienes, productos y servicios, así como los objetos o instrumentos, herramientas y dispositivos, para ser comprensibles, utilizables y practicables por todas las personas en condiciones de seguridad y comodidad y de la forma más autónoma y natural posible, por lo tanto implica la real probabilidad de ingresar, transitar y permanecer en un lugar de manera segura, confortable y autónoma, con los materiales, herramientas o mensajes necesarios, a fin de vivir de forma independiente y participar plenamente en todos los aspectos de la vida. (Fundación Once, 2011)

Además, el artículo 314 de la Constitución estipula que el Estado es responsable de la provisión de servicios públicos que respondan a los principios de universalidad, accesibilidad, continuidad y calidad y; según la Convención Internacional de los Derechos de las Personas con Discapacidad (2008) el Estado debe garantizar que los procedimientos, instalaciones y materiales electorales sean adecuados, accesibles y fáciles de entender y utilizar. 
Rampas de acceso a los espacios de votación

El CNE en el año 2013 escogió alrededor de 3402 recintos electorales según criterios mínimos de accesibilidad, generando como resultado, según el Informe de Observación Electoral de la Defensoría del Pueblo del Ecuador, que un $44 \%$ de los recintos tengan rampas de acceso a los espacios de votación en las elecciones generales de 2013.

Para las elecciones seccionales de 2014 se realizó una redistribución de los electores y las electoras en nuevos recintos más cercanos a sus domicilios, pero con menos espacio, provocando la instalación de las juntas receptoras del voto en los pisos superiores. Esto generó según el Informe de Observación Electoral del Consejo Nacional de Igualdad de Discapacidades, los observatorios de los derechos de las personas con discapacidad y las federaciones nacionales de y para la discapacidad, un descenso al 42\% de los recintos con rampas de acceso a los espacios de votación, cabe recalcar que además se observó, según este informe, que de estos recintos solo el 26\% disponía de rampas adecuadas y seguras.

Este descenso no quiere decir que la estrategia de acercamiento de los recintos electorales a los domicilios de los ciudadanos y ciudadanas no fue apropiado, al contrario, fue muy positivo debido a que se permitió que los mismos tomen menos tiempo en sufragar y utilicen menos recursos para movilizarse hasta el lugar. Cabe recalcar que las modificaciones de infraestructura de los recintos electorales no son de competencia del CNE.

\section{Transporte público para el acceso a los recintos electorales}

Según el informe de observación para el año 2013, un 95\% de los recintos contaba con acceso de transporte público. Luego de la redistribución de los electores y las electoras en nuevos recintos más cercanos a sus domicilios para el año 2014, según el informe de observación para este ańo, se evidenció un leve descenso al 86\% en las elecciones seccionales. 


\section{Señalética conforme a las normativas INEN}

Según los mismos informes, en 2013, el 47,68\% de los recintos contó con señalética que orientó a los y las votantes pertenecientes a grupos de atención prioritaria. En consecuencia para las elecciones seccionales de 2014 se diseñó y ubicó toda la información de la ubicación y funcionamiento de los espacios y servicios, tanto fuera como dentro de los recintos electorales, conforme a las normativas INEN del Ecuador, que como resultado, según el informe de observación 2014, el 62\% de los recintos electorales, en este año, contó con señalética que orientó a los y las votantes pertenecientes a grupos de atención prioritaria.

\section{Capacitación a integrantes de las Fuerzas Armadas y Policía Nacional}

En el Ecuador, los miembros de las Fuerzas Armadas y Policía Nacional cumplen un rol protagónico durante el proceso electoral ya que ellos brindan acompañamiento y garantizan el orden público. En este sentido, y con la finalidad de generar el mejor servicio para las personas con discapacidad y personas con movilidad reducida en general, el CNE incluyó en todos los materiales y espacios de capacitación a los integrantes de las Fuerzas Armadas y Policía Nacional, una temática sobre atención preferente en los recintos electorales, que entre sus contenidos más importantes se encontraba el derecho al voto asistido, el derecho al voto preferente, formas de atención según tipo discapacidad y según situaciones específicas del proceso electoral.

En consecuencia, según el informe de observación 2014, el 89\% de los integrantes de Fuerzas Armadas y Policía Nacional conocían información y formas de atención de las personas con discapacidad, que además benefició a los adultos mayores y las mujeres embarazadas. Sin duda, un gran avance en comparación con procesos electorales anteriores. 


\section{Mecanismos de atención para el sufragio de las personas con discapacidad}

La Convención Internacional sobre los Derechos de las Personas con Discapacidad, en su artículo 29, sobre la participación en la vida política y pública de las personas con discapacidad, establece que:

"Los Estados Partes garantizarán a las personas con discapacidad los derechos políticos y la posibilidad de gozar de ellos en igualdad de condiciones con las demás y se comprometerán asegurar su participación plena y efectivamente en la vida política y pública en igualdad, directamente o a través de representantes libremente elegidos, incluidos el derecho y la posibilidad de las personas con discapacidad a votar y ser elegidas, entre otras formas mediante la garantía de que los procedimientos, instalaciones y materiales electorales sean adecuados, accesibles y fáciles de entender y utilizar" (2008: 24).

En ese sentido, el CNE estableció los siguientes mecanismos:

\section{Mesa de atención preferente}

Con la intención de facilitar el tránsito y el ejercicio del derecho al sufragio de las personas con discapacidad y de movilidad reducida en general, se ubicaron 1762 mesas de atención preferente debidamente identificadas dentro de los recintos electorales. Así también, conforme a la voluntad de las personas con discapacidad manifestada a nivel nacional en las reuniones de socialización y consulta de los diversos mecanismos, y con la intención de no generar espacios paralelos de ejercicio de la ciudadanía, se ubicaron estas mesas solamente en recintos electorales con más de 10 juntas receptoras del voto.

El servicio ofrecido fue de información sobre el voto asistido y preferente, el uso de la plantilla en sistema braille, el apoyo para la movilización dentro de los recintos y el traslado de las papeletas de votación desde las juntas receptoras del voto hacia estas mesas. 
Según el informe de observación electoral 2013, solo el 68\% de los recintos electorales evidenciaron el servicio de la mesa de atención preferente, cabe recalcar que el personal fue voluntario de grupos juveniles de cada provincia.

En este sentido, para las elecciones seccionales de 2014 el CNE decidió contratar un personal exclusivo y debidamente capacitado para estas mesas y disponer para cada una de la información y señalética respectiva, es así que como resultado, según el informe de observación del mismo año, se aumentó al 83\% los recintos electorales que dispuso de este servicio.

De las 103481 personas atendidas en las mesas de atención preferente a nivel nacional durante las elecciones seccionales del año 2014, 10577 fueron mujeres embarazadas que representa el 10,23\%, 39741 fueron adultos mayores que representa el 38,40\% y 53163 fueron personas con algún tipo de discapacidad que representa el 51,37\%. El voto electrónico facilitó a las personas con discapacidad visual, por medio de sus ayudas técnicas, el ejercicio de su derecho al sufragio sin necesidad de ser asistido.

\section{Capacitación a coordinadores de recinto e integrantes de las juntas recepto-} ras del voto

Para los procesos electorales 2013 y 2014, el CNE capacitó alrededor de 250 mil miembros de las juntas receptoras del voto y coordinadores de recintos electorales, para lo cual se diseñaron materiales y se generaron espacios con información y metodologías específicas al proceso electoral.

Para generar el mejor servicio para las personas con discapacidad y personas con movilidad reducida en general, como política se incluyó en todos los materiales y espacios de capacitación a estos actores, una temática sobre "Atención Preferente en los Recintos Electorales" que entre sus contenidos más importantes se encontraba el derecho al voto asistido, el derecho al voto preferente, formas de atención según discapacidad y según situaciones específicas del proceso electoral. Este material se diseñó en coordinación con la Dirección Nacional de Capacitación y el Consejo Nacional de Discapacidades, así también con base a este material se gene- 
ró un curso virtual colocado en la página web del CNE abierto al público en general.

\section{Voto asistido}

De conformidad con la Convención Internacional de los Derechos de las Personas con Discapacidad y el Reglamento para la Participación Política de las Personas con Discapacidad del CNE, en su artículo 3, las personas con discapacidad tienen derecho al voto asistido, el cual pueden ejercerlo con la asistencia de una persona acompańante.

Se registra un incremento significativo del $42 \%$ del ejercicio del sufragio de manera asistida en el año 2012, a un 81\% en el 2014. De todas maneras este aumento si bien es cierto es positivo para el ejercicio del derecho al voto de las personas con discapacidad, este mecanismo no promueve una vida independiente como en el caso del voto electrónico con implementos o configuraciones audibles o la plantilla táctil (ver Gráfico 1).

\section{Gráfico 1.}

Personas con discapacidad que votaron de manera asistida

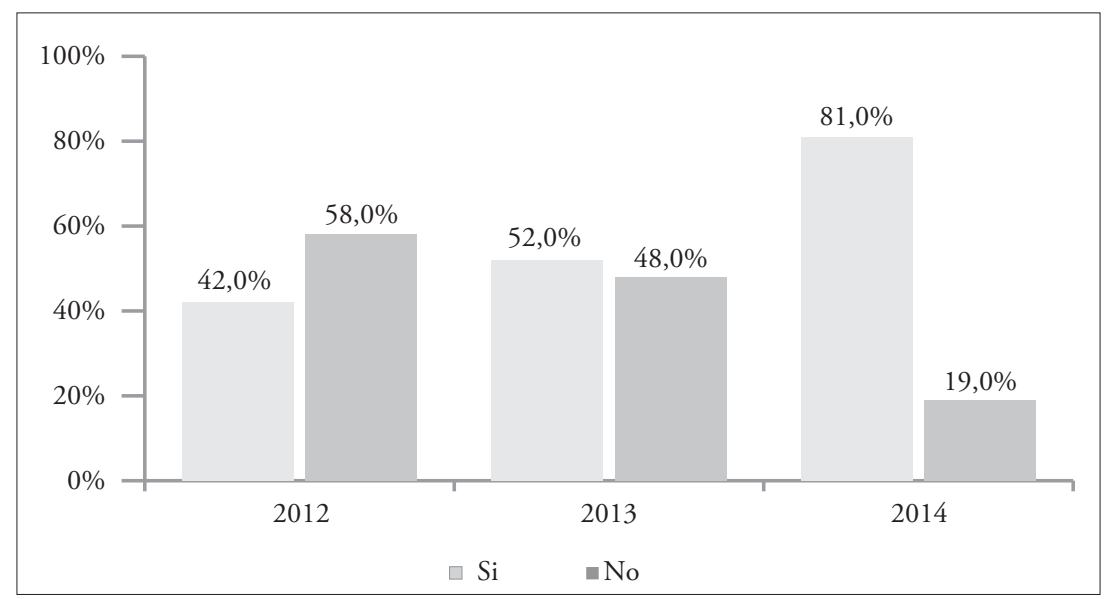

Fuente: Informe de observación electoral del Consejo Nacional de Igualdad de Discapacidades 2014 Elaborado por: Proyecto de Inclusión de Personas con Discapacidad - CNE 


\section{Materiales electorales accesibles}

Para las elecciones seccionales de 2014, las 11613270 papeletas electorales por cada una de las dignidades a elegir, se diseñaron con observaciones sobre diseño universal y accesibilidad a la información de parte de la Federación Ecuatoriana Pro Atención a la Persona con Discapacidad Intelectual, Síndrome de Down, Autismo y Parálisis Cerebral (FEPAPDEM).

Para las elecciones generales de 2013 se ubicaron alrededor de 6000 plantillas braille directamente en las juntas receptoras del voto de número 1 o múltiplos de 10, en este ańo, según el informe de observación electoral 2013, solo 54,9\% de los recintos electorales informó que sus juntas receptoras del voto disponía de este material electoral.

En vista de la necesidad de facilitar la votación independiente de las personas con discapacidad visual, para las elecciones seccionales del año 2014 se imprime la misma cantidad de plantillas y además se dispone también para las dignidades de Prefecturas y Alcaldías, las cuales fueron ubicadas en las mesas de atención preferente. Esta estrategia provocó que el $70 \%$ de los recintos electorales dispusiera para la ciudadanía de este material electoral, según el informe de observación electoral 2014.

Así también según los informes de las Mesas de Atención Preferente a nivel nacional, se reportó el uso de alrededor de 1617 plantillas braille durante varias ocasiones, sin poder cuantificar aun la cantidad de personas beneficiadas con exactitud de este material electoral. De todas maneras de las aproximadamente 40000 personas con discapacidad visual empadronadas en el Ecuador, solo el 10\% manifiesta que dominan el sistema braille. Por lo tanto lejos de ser un argumento para retirarlas, es un llamado de atención para conservar y no dejar que se pierda el sistema de lecto escritura a causa del avance de la tecnología. Aun así es evidente que si se desarrolla el voto electrónico en el país, desaparecería este instrumento. 


\section{Voto en casa}

Conforme al artículo 111 y el 115 del Código de la Democracia, el CNE garantizará los mecanismos idóneos para que las personas con discapacidad puedan ejercer su derecho al sufragio, incorporándolos en la normativa electoral que se dicte, así también, reglamentará la forma de votación que deba ser implementada para los casos de personas cuya discapacidad impida el ejercicio del sufragio.

Por lo tanto, el CNE en coordinación con las federaciones nacionales de personas con discapacidad, amplió el Proyecto "Voto en Casa", que consistió en la conformación de Juntas Receptoras del Voto Móviles (JRVM) con la finalidad de acercar el ejercicio del derecho al sufragio hasta los domicilios de las personas con discapacidad previamente inscritas, en 12 provincias del país como: Tungurahua, Santa Elena, Imbabura, Carchi, Manabí, Morona Santiago, Chimborazo, Loja, Bolívar, Azuay, Santo Domingo de los Tsáchilas y Napo.

Para la definición de los electores en casa se solicitó una base de datos de personas con discapacidad física superior al 75\% y mayores de 65 años al CONADIS y al MSP. Se realizó una llamada telefónica a más de 1000 personas para ofrecerles el servicio de votación en casa y posterior a su respuesta positiva, una visita al domicilio que permitió registrar su voluntad a través de una credencial de votación. De esta cantidad de personas contactadas, aceptaron registrarse 320, sufragaron 275 y se conformaron 49 JRVM. Para el funcionamiento de las JRVM se contrataron 245 miembros de JRV, 49 integrantes de las Fuerzas Armadas y 98 integrantes de la Policía Nacional (ver Tabla 2). 
Tabla 2.

Resultados del Proyecto "Voto en Casa"

\begin{tabular}{|c|c|c|c|c|c|c|c|}
\hline Provincia & $\begin{array}{c}\text { \#Electores } \\
\text { en casa }\end{array}$ & Cantón & $\begin{array}{c}\text { \# Electores } \\
\text { en casa por } \\
\text { cantón }\end{array}$ & $\begin{array}{c}\text { No } \\
\text { presentados }\end{array}$ & Fallecidos & Votantes & $\begin{array}{l}\% \text { de } \\
\text { servidos }\end{array}$ \\
\hline Azuay & 39 & Cuenca & 39 & 2 & 0 & 37 & 100,0 \\
\hline Bolívar & 14 & Guaranda & 14 & 0 & 1 & 13 & 100,0 \\
\hline \multirow{2}{*}{ Carchi } & \multirow{2}{*}{25} & Tulcán & 19 & 1 & 1 & 17 & 100,0 \\
\hline & & Montúfar & 6 & 0 & 1 & 5 & 100,0 \\
\hline Chimborazo & 15 & Riobamba & 15 & 0 & 1 & 14 & 100,0 \\
\hline \multirow{2}{*}{ Imbabura } & \multirow{2}{*}{19} & Ibarra & 11 & 1 & 2 & 8 & 100,0 \\
\hline & & Otavalo & 8 & 1 & 0 & 7 & 100,0 \\
\hline Loja & 23 & Loja & 23 & 4 & 1 & 18 & 100,0 \\
\hline Manabí & 80 & Manta & 80 & 12 & 5 & 63 & 100,0 \\
\hline \multirow{2}{*}{$\begin{array}{l}\text { Morona } \\
\text { Santiago }\end{array}$} & \multirow{2}{*}{9} & Macas & 3 & 0 & 0 & 3 & 100,0 \\
\hline & & Sucua & 6 & 1 & 0 & 5 & 100,0 \\
\hline Napo & 4 & Tena & 4 & 0 & 0 & 4 & 100,0 \\
\hline \multirow{3}{*}{ Santa Elena } & \multirow{3}{*}{47} & $\begin{array}{l}\text { Santa } \\
\text { Elena } \\
\end{array}$ & 22 & 0 & 2 & 20 & 100,0 \\
\hline & & Libertad & 18 & 0 & 0 & 18 & 100,0 \\
\hline & & Salinas & 7 & 0 & 1 & 6 & 100,0 \\
\hline $\begin{array}{c}\text { Santo } \\
\text { Domingo } \\
\text { de los } \\
\text { Tsáchilas }\end{array}$ & 17 & $\begin{array}{l}\text { Santo } \\
\text { Domingo }\end{array}$ & 17 & 1 & 2 & 14 & 100,0 \\
\hline \multirow{2}{*}{ Tungurahua } & \multirow{2}{*}{24} & Ambato & 20 & 0 & 0 & 20 & 100,0 \\
\hline & & Pelileo & 4 & 1 & 0 & 3 & 100,0 \\
\hline Total & 316 & & 316 & 24 & 17 & 275 & 100,0 \\
\hline
\end{tabular}

Fuente: CNE, 2014

Elaboración: Proyecto de Inclusión de Personas con Discapacidad 


\section{Difusión}

Como complemento informativo importante de todo proceso electoral y con el fin de que todas las personas con discapacidad y movilidad reduci$\mathrm{da}$ en general conozcan sobre sus derechos y deberes de elegir, ser elegido, participar en el proceso electoral y normativas y mecanismos de votación, se construyeron más de 73 mil materiales de difusión en diversos formatos según las necesidades específicas de cada discapacidad y se distribuyeron a través de 274 eventos de difusión donde participaron más de 1 331 organizaciones de personas con discapacidad, grupos prioritarios con voto facultativo en general y 125 organizaciones políticas. Así también se realizaron 116188 llamadas telefónicas informativas sobre los mecanismos de sufragio desde el centro de llamadas contratado por el CNE.

Ejercicio del sufragio de las personas con discapacidad

Conforme los artículos 111 y 115 del Código de la Democracia, el CNE puso en marcha los siguientes mecanismos:

\section{a. Sufragantes con discapacidad}

En cada proceso electoral desde el año 2009 existe un incremento sostenido de aproximadamente un 5\% a 10\% en la identificación de las personas con discapacidad en el Registro Electoral, sin embargo en la asistencia a los recintos electorales se muestra un incremento importante, principalmente en las elecciones del año 2011 y del 2014.

Este incremento se podría interpretar como el resultado de la aplicación de políticas destinadas a elevar el número de electores con discapacidad y la apertura de espacios de participación en la toma de decisiones de lo público, es así que esto es directamente proporcional con la participación política de los y las ciudadanas. De todas maneras aún se evidencia una disparidad de género en el ejercicio del sufragio debido a que el 59\% de los votantes son hombres y el $41 \%$ son mujeres (ver Gráfico 2). 
Gráfico 2.

Sufragantes con discapacidad

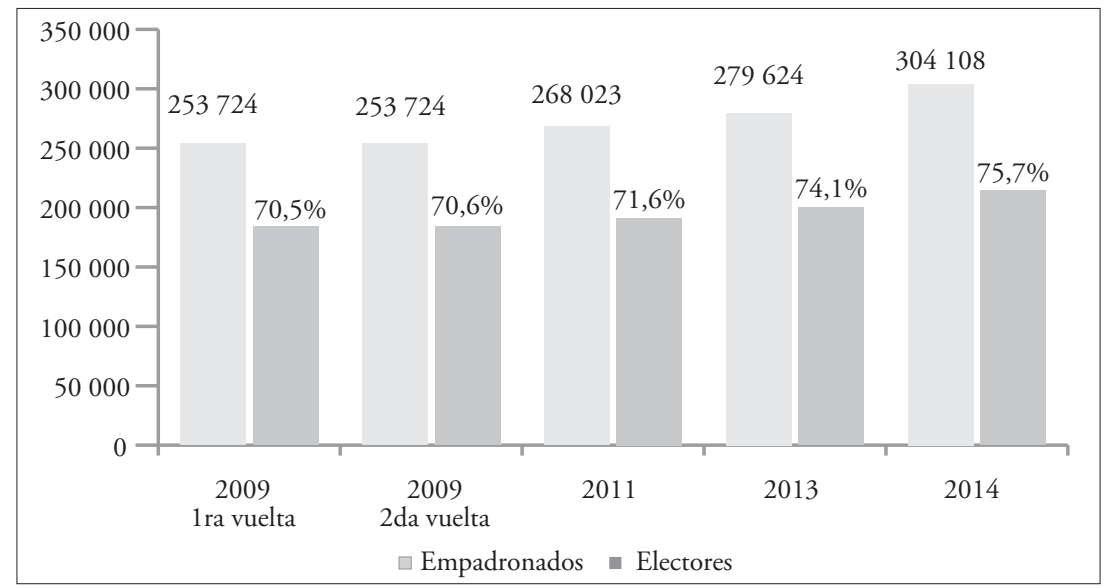

Elaboración: Proyecto de Inclusión de Personas con Discapacidad - CNE, 2014

Fuente: Dirección Nacional de Estadística - CNE, 2014

\section{b. Voto en el exterior 2013}

De los 285753 electores empadronados en el exterior para las elecciones del 17 de febrero de 2013, las personas con discapacidad en esta misma condición representan el 0,22\% del total. En relación a la media, la discapacidad física en el exterior representa por lo menos un $10 \%$ más que en la población dentro del territorio. De los 642 inscritos con discapacidad en el exterior, la mayor cantidad se encuentra en Europa, Asia y Oceanía.

\section{Derecho a ser elegido}

Según el artículo 61 de la Constitución, los y las ecuatorianas gozan, entre otros derechos, el derecho a elegir y ser elegidos, lo cual también contempla en el artículo 29 de la Convención Internacional sobre los Derechos de las Personas con Discapacidad, el cual estipula: "los Estados partes garantizarán la presentación efectiva como candidatas en 
las elecciones, ejercer cargos y desempeñar cualquier función pública a todos los niveles de gobierno, facilitando el uso de nuevas tecnologías y tecnologías de apoyo cuando proceda" (2008: 24). En este sentido, a continuación se presenta un resumen de la participación de las personas con discapacidad como candidatas y candidatos principales y suplentes en los procesos electorales desde 2002 hasta 2014.

Candidatas principales y suplentes 2002-2014

Durante la primera década del siglo XX se registró un descenso de la participación de las personas con discapacidad hasta el 2006, a partir de esa fecha se evidencia un alza significativa desde el 2009 hasta el 2014.

Hasta el momento, en el 2014 se ha presentado el porcentaje más alto de participación de personas con discapacidad como candidatos en relación a las elecciones anteriores. Cabe recalcar que este grupo de personas representa el 2,4\% del total de electores aproximadamente y por lo tanto aún es insuficiente su participación (ver Gráfico 3).

\section{Gráfico 3.}

Candidaturas 2002 - 2014

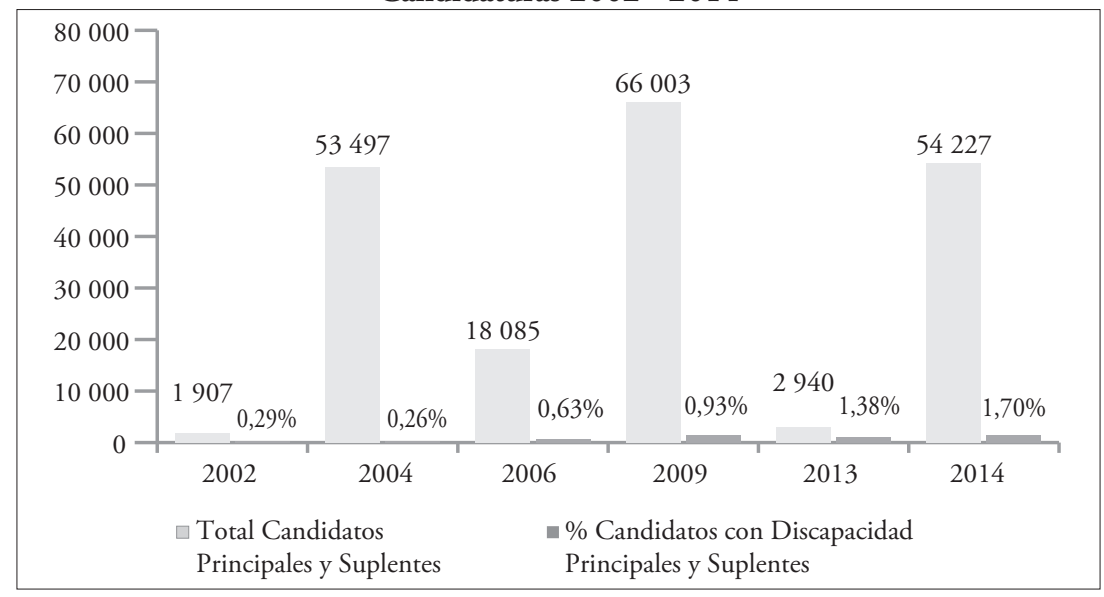

Elaboración: Proyecto de Inclusión de Personas con Discapacidad - CNE

Fuente: Dirección Nacional de Registro Electoral - CNE 
De todas maneras aún se evidencia una disparidad de género en las candidaturas debido a que el $76,8 \%$ son hombres y el $23,2 \%$ son mujeres, así también con respecto del tipo de discapacidad, debido a que el $78 \%$ tiene una discapacidad física; en relación a las dignidades, el mayor número de candidaturas responde a las dignidades para las Juntas Parroquiales Rurales.

\section{Gráfico 4.}

Candidaturas según sexo

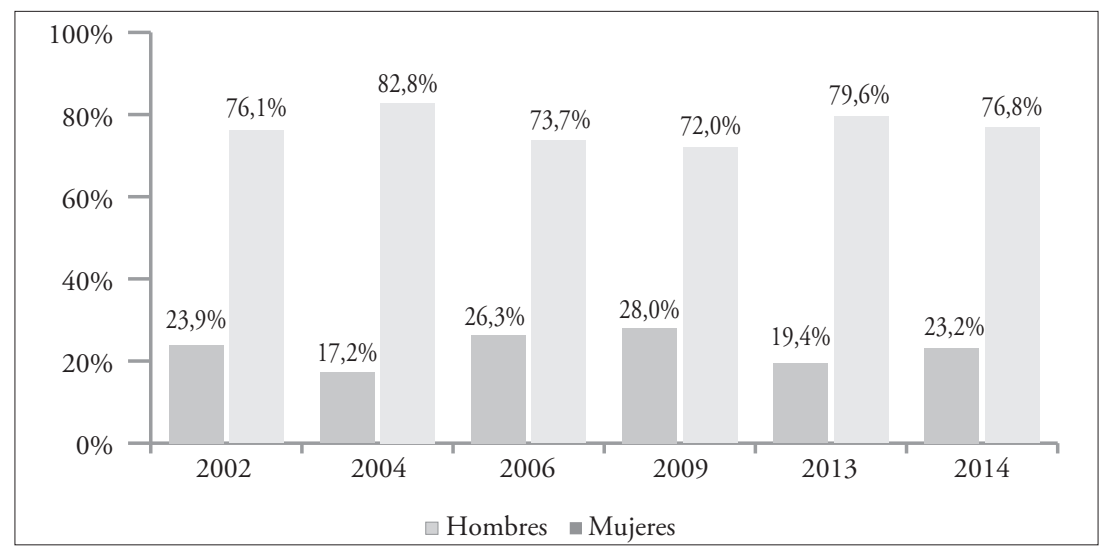

Elaboración: Proyecto de Inclusión de Personas con Discapacidad - CNE Fuente: Dirección Nacional de Registro Electoral - CNE

Personas con discapacidad elegidas como autoridades principales y suplentes: $2002-2014$

La elección de personas con discapacidad durante la primera década del siglo XX evidencia un ascenso importante desde el proceso electoral del año 2006, siendo en el año 2013 la mayor cantidad registrada de autoridades con discapacidad electas para el año 2014 se registra un descenso significativo. 


\section{Gráfico 5.}

Candidatos principales y suplentes según dignidad y género

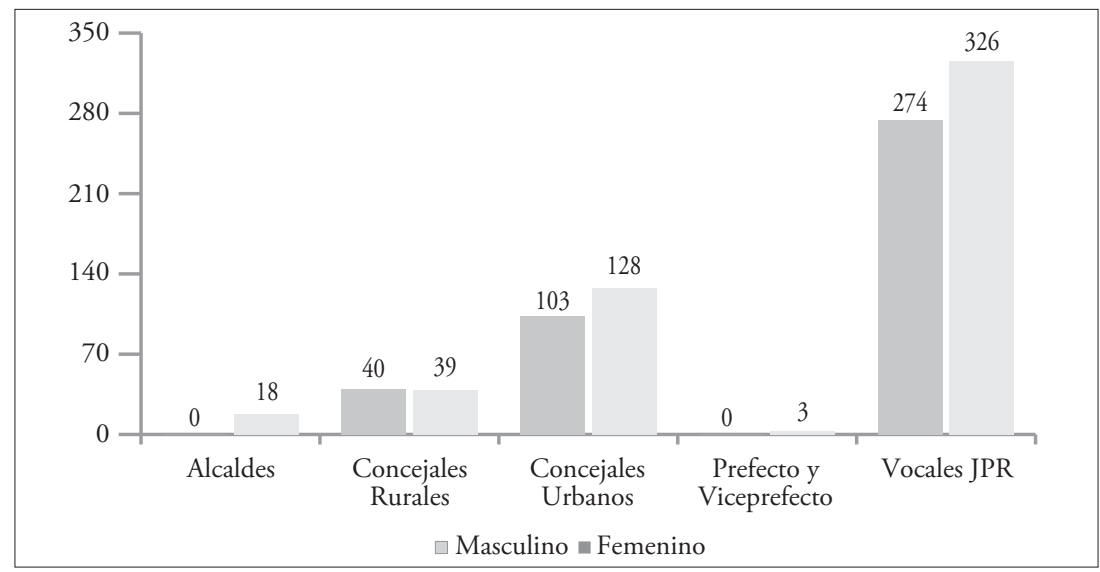

Elaboración: Proyecto de Inclusión de Personas con Discapacidad - CNE Fuente: Dirección Nacional de Registro Electoral - CNE

\section{Gráfico 6.}

\section{Autoridades principales y suplentes con discapacidad $2002-2014$}

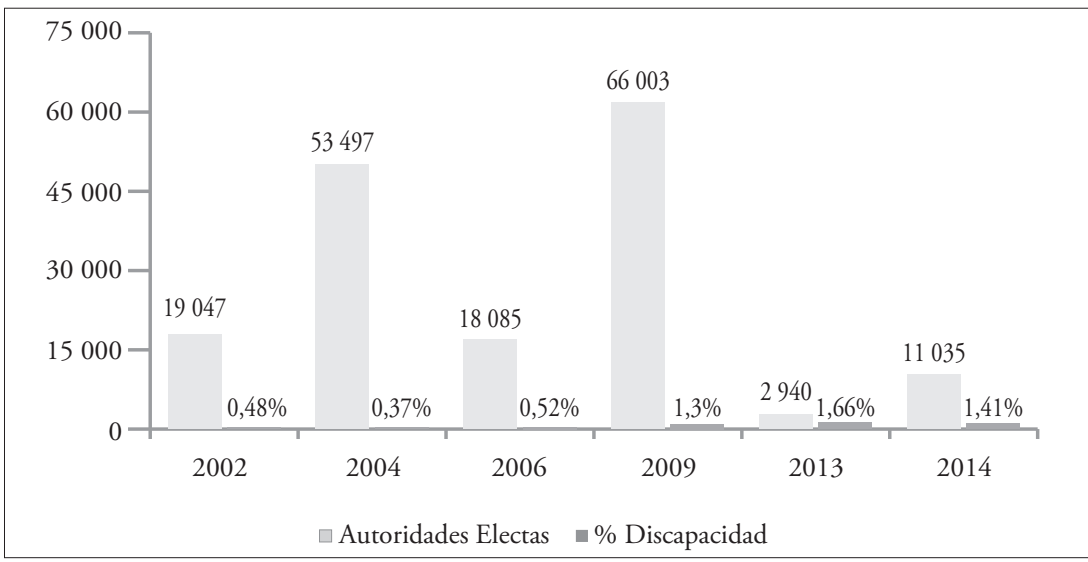

Elaboración: Proyecto de Inclusión de Personas con Discapacidad - CNE

Fuente: Dirección Nacional de Registro Electoral - CNE 
Además, durante la primera década del siglo XX se observa una insuficiente participación de las mujeres con discapacidad como autoridades; de todas maneras, existe un aumento muy significativo desde el 2006 como el mayor año que se registró su participación, así también se muestra un descenso de casi un $8 \%$ en la misma hasta el 2013 tal y como se observa en el Gráfico 7.

\section{Gráfico 7.}

Autoridades con discapacidad electas por sexo $2002-2014$

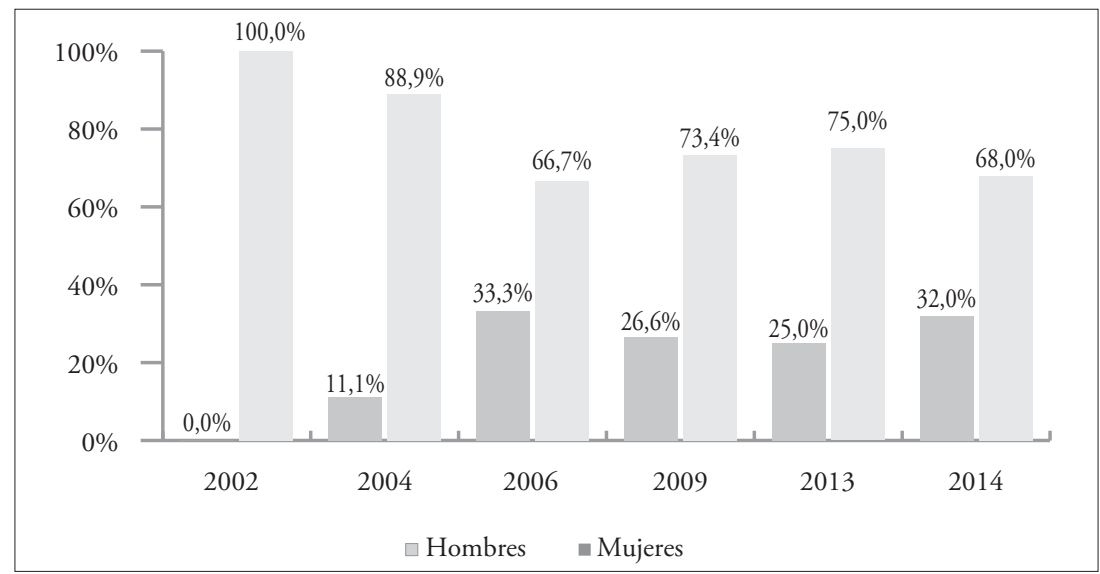

Elaboración: Proyecto de Inclusión de Personas con Discapacidad - CNE

Fuente: Dirección Nacional de Registro Electoral - CNE

\section{Derecho a participar del proceso electoral como evento público}

La construcción de la ciudadanía de una persona implica el ejercicio de sus derechos humanos y la participación efectiva en los espacios de decisión pública. Por un lado, según el artículo 48 de la Constitución, el Estado adoptará a favor de las personas con discapacidad medidas que fomenten su participación política, social, cultural, educativa y econó- 
mica. Por otro lado, según el Código de la Democracia, en su artículo 2, establece que las ecuatorianas y ecuatorianos tienen derecho a elegir y ser elegidos, a participar en los asuntos de interés público e intervenir como veedores u observadores en los procesos electorales.

De esta manera, el CNE motivó campañas para garantizar la participación de las personas con discapacidad en espacios de decisión pública. Estos son:

\section{Observadores electorales}

El CNE junto con el CONADIS promovió por segunda vez una campaña para que las personas con discapacidad se inscriban como observadores electorales para los procesos electorales 2013 y 2014. Esta campaña registro un aumento de inscripciones de 18 personas con discapacidad en las elecciones del 2013 a 786 en el 2014, de todas maneras por no cumplir con los requisitos establecidos en la Ley solo se aceptó a 490 ciudadanos como observadores.

Así también, con la intención de que la discapacidad se integre como un eje trasversal en la observación electoral, se agregaron las temáticas de discapacidad en las 1200 guías que se entregaron a los observadores nacionales e internacionales. Además se coordinó la inclusión de variables de observación sobre discapacidad en la Observación de la Defensoría del Pueblo.

De todas maneras existió un fuerte número de personas que no pudieron ser observadores debido a la presentación de documentos fuera del tiempo estipulado para la inscripción y a que éstas se encontraban inscritas en alguna organización política.

\section{Apoyo a la campaña "Tienen Derecho a Votar"}

Según un estudio generado de parte del Proyecto de Inclusión de Personas con Discapacidad del CNE, se determinó que esta población ma- 
nifiesta como problema principal el insuficiente e inaccesible acceso al transporte para movilizarse hacia los recintos electorales.

Es así que esta campaña respondió a esta necesidad promoviendo además el derecho a elegir de las personas con discapacidad y movilidad reducida, esta iniciativa de la sociedad civil se ha desarrollado desde hace 6 años durante los últimos 12 procesos electorales, su direccionamiento está a cargo de la Corporación Gestión Ecuador, las Federaciones Nacionales de Discapacidad y el medio de comunicación Teleamazonas, Las actividades se coordinan con la Policía Nacional, grupos juveniles, transportistas y por segunda ocasión con el CNE, a través de sus Delegaciones Provinciales Electorales.

A nivel nacional participaron para la movilización 4081 personas con discapacidad, 503 personas mayores de 65 ańos, 1599 voluntarios con vehículo de apoyo para la movilización y 2555 voluntarios sin vehículo de apoyo para la movilización.

\section{Conclusiones}

Se puede considerar que el origen y la causa de la exclusión a través de la historia hasta nuestro tiempo ha sido la forma de ver a los seres humanos como diferentes e inferiores y no como diferentes e iguales, lo cual provoca una barrera en la participación ciudadana y una separación de la esfera pública de los individuos discriminados. De todas maneras hay que desarrollar todavía la concepción de lo diferente, no como aquellos elementos que nos clasifican o nos agrupan, sino como aquellos que nos asemejan y que nos unen.

La democracia moderna garantiza los derechos ciudadanos por igual, lo que permite el ejercicio de los mismos a medida de la voluntad de cada uno. Por lo tanto, es obligatoriedad de las instituciones estatales, la garantía de los derechos de los ciudadanos, y de estos, la responsabilidad de su ejercicio.

Es preciso señalar que hay una diferencia conceptual entre inclusión e integración, ya que desde estas definiciones es donde se construye la 
política pública y la convivencia social en general; entonces, la apuesta es acercarnos a la integración por sobre la inclusión. La integración es fusionar en todos los ámbitos, los intereses y necesidades de la ciudadanía tanto de una manera individual como colectiva y consolidar una nueva forma de convivencia en diversidad, e incluso en armonía con la naturaleza. Además debe ser el resultado de la libre decisión de participar, consiguiendo así el verdadero fin del desarrollo, que es la libertad de cada ser humano, de autodefinirse o autoconstruirse, cualquiera que sea el contexto o el espacio donde viva.

Ya en el ámbito público, para que un Estado aporte a la integración social, este debe establecer normativas, recursos y estructuras organizativas, que, de una manera transversal, se institucionalicen y generen productos de impacto que conlleven a este fin. Además todo proceso o intervención social debe ser un trabajo en conjunto con organizaciones que representan a los distintos grupos y actores sociales.

En este sentido, el Ecuador ha dado pasos significativos hacia una integración social que reúne a distintos grupos, particularmente, a las personas con discapacidad. Para esto, la Función Electoral ha emprendido en los últimos ańos, una política pública que promueve la participación política de estas poblaciones. De igual forma, un sinnúmero de actores ciudadanos también han contribuido al mismo objetivo generando iniciativas en favor de la participación política de las personas con discapacidad. El ejercicio de los derechos de participación política de las personas con discapacidad en el Ecuador muestra un avance significativo durante la última década, de todas maneras podemos evidenciar un descenso considerable en la cantidad de autoridades en esta situación luego de las elecciones seccionales del 2014. Es así que se hace necesaria la capacitación de este y otros grupos poblacionales en particular y promocionar su participación en la toma de decisiones en la administración de lo público, caso contrario sería responsabilidad de los mismos la insuficiente política pública en beneficio de sus realidades.

El camino no ha sido fácil, de hecho, aún es necesaria la potenciación de las capacidades de los funcionarios de las instituciones públi- 
cas, tanto en sus instancias centrales como de sus dependencias con la finalidad de responder a las necesidades poblacionales de una manera efectiva, y conforme al contexto de cada provincia, propiciando así el desarrollo endógeno del país.

Para finalizar, es preciso señalar que las condiciones y la calidad de vida de las personas y la satisfacción de sus necesidades particulares, tiene una relación directa con su nivel de participación ciudadana, y por tanto, con su participación política e influencia en la administración de lo público. De ahí la necesidad de que los organismos electorales incorporen como parte de su institucionalidad, una visión integradora, que promueva un involucramiento más activo y más participativo de los actores tradicionalmente excluidos.

\section{Bibliografía}

Boisier, S. (2004). Desarrollo endógeno: ¿Para qué?, ¿Para quién? Chile: DT, ILPES.

Cisneros, Isidoro (2002). "Génesis de la política absoluta”, en Red de Revistas Científicas de América Latina, el Caribe, España y Portugal. Vol. XX, No. 3, septiembre-diciembre: 625-639.

Fleury, S. (2003). "La expansión de la ciudadanía”. Visita de julio 2014. Disponible en: http://www.ebape.fgv.br/comum/arq/pp/peep/ cap_liv/laexpansion_laciudadania.pdf

Fundación ONCE (2011). "Accesibilidad Universal y Diseño para todos Arquitectura y Urbanismo”. Visita de julio 2014. Disponible en: http://www.fundaciononce.es/sites/default/files/docs/Accesibilidad $\% 2520$ universal\%2520y\%2520dise\%C3\%B1o\%2520para\%2520todos_1.pdf

García, C. (2003). “Cuerpo y alma de Homero a Platón”. Visita de junio 2014. Disponible en http://antiqua.gipuzkoakultura.net/cuerpo_y_alma.php.

Giménez, F. (2008). "La crítica de la democracia.”, en Razón Espa- 
ñola: Revista bimestral de pensamiento. No.152, julio: 331-326.

Organización Mundial de la Salud (2011). "Informe mundial sobre la discapacidad". Visita de junio 2014. Disponible en: http://www. who.int/disabilities/world_report/2011/summary_es.pdf

Real Academia de la Lengua Española (2001). Diccionario de la lengua española (22.a ed.). Visita de junio 2014. Disponible en: http:// www.rae.es/

Martínez, T. (2013). “La Mujer, eso”. Visita de julio 2014. Disponible en http://martinezdelezea.com/la-mujer-eso/

Moreno, L. (2012). "Discurso en la Cumbre Continental América Solidaria en Quito". Visita de julio 2014. Disponible en: http:// www.vicepresidencia.gob.ec/discurso-del-vicepresidente-lenin-moreno-en-la-inauguracion-del-congreso-america-solidaria.

Normativa y documentos oficiales

Constitución de la República del Ecuador (2008). Asamblea Constituyente. Ciudad Alfaro.

Convención Internacional sobre los Derechos de las Personas con Discapacidad (2008). Organización de las Naciones Unidas. Nueva York.

Ley Orgánica Electoral y de Organizaciones Políticas de la República del Ecuador, Código de la Democracia (2009). Asamblea Nacional. Quito: Suplemento R.O. 578 del 27 de abril.

Reglamento de Participación Política de las Personas con Discapacidad (2012). Consejo Nacional Electoral del Ecuador. Quito 